\title{
(2) OPEN ACCESS \\ Emergency management of adrenal insufficiency in children: advocating for treatment options in outpatient and field settings
}

\author{
Bradley S Miller (D) , 'Sandra P Spencer, ${ }^{2}$ Mitchell E Geffner, ${ }^{3}$ Evgenia Gourgari, ${ }^{4}$ \\ Amit Lahoti, ${ }^{5}$ Manmohan K Kamboj, ${ }^{2}$ Takara L Stanley, ${ }^{6}$ Naveen K Uli, ${ }^{7}$ \\ Brandy A Wicklow, ${ }^{8}$ Kyriakie Sarafoglou ${ }^{1}$
}

For numbered affiliations see end of article.

\section{Correspondence to Dr Bradley S Miller, Department of Pediatrics, University of Minnesota Masonic Children's Hospital, 2450 Riverside Ave, Minneapolis, MN 55454 USA; mille685@umn.edu}

The work has been presented at Pediatric Academic Society Meeting 2018, 'Year In Review: Emergency Management of Adrenal Insufficiency in Children: A Clinical Practice Guideline', Toronto, Ontario, Canada, May 2018.

Accepted 7 February 2019 Published Online First 28 February 2019

\section{ABSTRACT}

Adrenal insufficiency (Al) remains a significant cause of morbidity and mortality in children with 1 in 200 episodes of adrenal crisis resulting in death. The goal of this working group of the Pediatric Endocrine Society Drug and Therapeutics Committee was to raise awareness on the importance of early recognition of $\mathrm{Al}$, to advocate for the availability of hydrocortisone sodium succinate (HSS) on emergency medical service (EMS) ambulances or allow EMS personnel to administer patient's HSS home supply to avoid delay in administration of lifesaving stress dosing, and to provide guidance on the emergency management of children in adrenal crisis. Currently, hydrocortisone, or an equivalent synthetic glucocorticoid, is not available on most ambulances for emergency stress dose administration by EMS personnel to a child in adrenal crisis. At the same time, many States have regulations preventing the use of patient's home HSS supply to be used to treat acute adrenal crisis. In children with known Al, parents and care providers must be made familiar with the administration of maintenance and stress dose glucocorticoid therapy to prevent adrenal crises. Patients with known Al and their families should be provided an Adrenal Insufficiency Action Plan, including stress hydrocortisone dose (both oral and intramuscular/intravenous) to be provided immediately to EMS providers and triage personnel in urgent care and emergency departments. Advocacy efforts to increase the availability of stress dose HSS during EMS transport care and add HSS to weight-based dosing tapes are highly encouraged.

\section{INTRODUCTION}

\section{Prismatic clinical scenario}

A 9-year-old boy presented to a local emergency department (ED) with chronic abdominal pain, acute onset of nausea and vomiting for the previous 24 hours. Physical examination revealed an ill-appearing, thin male with tachycardia (pulse $110 \mathrm{bpm}$ ), mild hypotension $(85 / 60 \mathrm{~mm} \mathrm{Hg})$, signs of dehydration, and hyperpigmentation. Laboratory testing showed hyponatremia (sodium $129 \mathrm{mEq} / \mathrm{L}$ ), hyperkalemia (potassium $5.8 \mathrm{mEq} / \mathrm{L}$ ) and hypoglycemia (glucose $55 \mathrm{mg} / \mathrm{dL}$ ). Despite urgent fluid resuscitation with 2 intravenous boluses of normal saline and a bolus of 10\% dextrose, hypotension persisted. Due to clinical and biochemical features suggestive of primary adrenal insufficiency (AI), blood was drawn for measurement of adrenocorticotropic hormone (ACTH) and cortisol levels prior to administering $75 \mathrm{mg}$ of intravenous hydrocortisone sodium succinate (Solu-Cortef). He was admitted and diagnosis confirmed. Treatment was initiated with hydrocortisone and fludrocortisone. The patient and family received education for the management of primary $\mathrm{AI}$ and prevention of adrenal crises.

Two years later he developed acute gastroenteritis with fever, vomiting and diarrhea while visiting his grandparents in a rural area. He received triple his usual dose of oral hydrocortisone, but vomited within 10 minutes. Grandparents had hydrocortisone sodium succinate available for intramuscular injection, but did not know how to administer it and called 911. The patient was unresponsive on arrival of the ambulance 20 minutes later. Grandparents informed the emergency medical technicians (EMT) that he needs to receive hydrocortisone sodium succinate intramuscularly for AI. Due to emergency medical services (EMS) policy, the EMTs were not allowed to administer the child's personal supply of hydrocortisone sodium succinate and did not have an alternative medication on the ambulance. Glucometer revealed a blood glucose of $30 \mathrm{mg} / \mathrm{dL}$. While EMTs attempted to place an intravenous catheter, he experienced a seizure. He was intubated and received intravenous dextrose with cessation of the seizure. He was transported to a local ED that was 30 minutes away. In the ED, he was given $75 \mathrm{mg}$ intravenous hydrocortisone sodium succinate and was admitted to the intensive care unit where he later died of complications related to prolonged hypoglycemia and aspiration pneumonitis.

\section{BACKGROUND}

Adrenal crisis is a life-threatening condition that can be prevented by recognition in which patients with AI must receive additional 
Table 1 Congenital causes of adrenal insufficiency

\begin{tabular}{|c|c|c|}
\hline Condition & $\begin{array}{l}\text { Affected } \\
\text { gene }\end{array}$ & Clinical phenotype \\
\hline \multicolumn{3}{|l|}{ Primary } \\
\hline \multicolumn{3}{|l|}{$\mathrm{CAH}$} \\
\hline 21 - $\alpha$-hydroxylase deficiency & CYP21A2 & $\begin{array}{l}46, X X \text { DSD/androgen excess; } \\
\text { salt-wasting }\end{array}$ \\
\hline $\begin{array}{l}\text { 3- } \beta \text {-hydroxysteroid } \\
\text { dehydrogenase deficiency }\end{array}$ & $H S D 3 B 2$ & $\begin{array}{l}\text { Ambiguous genitalia/salt- } \\
\text { wasting }\end{array}$ \\
\hline 11- $\beta$-hydroxylase deficiency & CYP11B2 & $\begin{array}{l}\text { 46,XX DSD/androgen excess; } \\
\text { hypertension (not infants) }\end{array}$ \\
\hline $\begin{array}{l}\text { P450 side-chain cleavage } \\
\text { syndrome }\end{array}$ & CYP11A & $\begin{array}{l}46, X Y \text { DSD; salt-wasting, } \\
\text { hypogonadism }\end{array}$ \\
\hline Lipoid hyperplasia & StAR & $\begin{array}{l}46, X Y \text { DSD; salt-wasting; } \\
\text { hypogonadism }\end{array}$ \\
\hline $\begin{array}{l}\text { P450 oxidoreductase } \\
\text { deficiency (PORD) }\end{array}$ & POR & $\begin{array}{l}46, X Y \text { DSD, salt-wasting, } \\
\text { hypogonadism, Antley-Bixler } \\
\text { malformation; altered drug } \\
\text { metabolism }\end{array}$ \\
\hline \multirow[t]{3}{*}{ Congenital adrenal hypoplasia } & $\begin{array}{l}\text { SF-1 } \\
\text { (NR5A1) }\end{array}$ & $\begin{array}{l}46, X Y \text { DSD, gonadal } \\
\text { insufficiency }\end{array}$ \\
\hline & $\begin{array}{l}D A X-1 \\
(N R O B 1)\end{array}$ & $\begin{array}{l}\text { Hypogonadotropic } \\
\text { hypogonadism }\end{array}$ \\
\hline & CDKN1C & $\begin{array}{l}\text { IMAGe syndrome (intrauterine } \\
\text { growth retardation, } \\
\text { metaphyseal dysplasia, genital } \\
\text { anomalies) }\end{array}$ \\
\hline Triple A or Allgrove & $A A A S$ & Achalasia, alacrima \\
\hline $\begin{array}{l}\text { Isolated familial glucocorticoid } \\
\text { deficiency (FGD) }\end{array}$ & $\begin{array}{l}M C 2 R \\
\text { MRAP }\end{array}$ & $\begin{array}{l}\text { Tall stature, normal } \\
\text { mineralocorticoid production }\end{array}$ \\
\hline FGD-DNA repair defect & MCM4 & $\begin{array}{l}\text { NK-cell defect, short stature, } \\
\text { recurrent viral infections, } \\
\text { microcephaly, chromosomal } \\
\text { breakage }\end{array}$ \\
\hline Glucocorticoid resistance & GCCR & $\begin{array}{l}\text { Mineralocorticoid/androgen } \\
\text { excess }\end{array}$ \\
\hline \multicolumn{3}{|l|}{ Metabolic diseases } \\
\hline Adrenoleukodystrophy & $A B C D 1$ & Neurologic deterioration \\
\hline Zellweger & PEX & Cerebrohepatorenal syndrome \\
\hline Smith-Lemli-Opitz & DHCR7 & $\begin{array}{l}46, X Y \text { sex reversal, polydactyly, } \\
\text { mental retardation }\end{array}$ \\
\hline Wolman & LIPA & Hepatomegaly \\
\hline \multicolumn{3}{|l|}{ Mitochondrial disease } \\
\hline Kearns-Sayre & & Ophthalmoplegia, myopathy \\
\hline \multicolumn{3}{|l|}{ Secondary: hypothalamus } \\
\hline Holoprosencephaly & $\begin{array}{l}\text { GLI2, } \\
\text { FGF8 }\end{array}$ & \\
\hline \multicolumn{3}{|l|}{ CRH deficiency } \\
\hline \multicolumn{3}{|l|}{ Maternal hypercortisolemia } \\
\hline \multicolumn{3}{|c|}{ Secondary: pituitary/hypothalamus } \\
\hline Isolated ACTH deficiency & TPIT & \\
\hline \multirow{5}{*}{$\begin{array}{l}\text { Multiple anterior pituitary } \\
\text { hormone deficiencies due to } \\
\text { pituitary aplasia/hypoplasia }\end{array}$} & HESX1 & $\begin{array}{l}\text { Septo-optic dysplasia (optic } \\
\text { nerve hypoplasia), nystagmus }\end{array}$ \\
\hline & PROP1 & \\
\hline & LHX4 & \\
\hline & OTX2 & $\begin{array}{l}\text { Anophthalmia, developmental } \\
\text { delay }\end{array}$ \\
\hline & sox3 & $\begin{array}{l}\text { X linked, mental retardation, } \\
\text { ectopic posterior pituitary }\end{array}$ \\
\hline Isolated ACTH deficiency & $\begin{array}{l}\text { TPIT } \\
\text { (TBX19) }\end{array}$ & \\
\hline
\end{tabular}

Continued

\begin{tabular}{lll}
\hline Table 1 Continued & & \\
\hline Condition & $\begin{array}{l}\text { Affected } \\
\text { gene }\end{array}$ & Clinical phenotype \\
\hline Proopiomelanocortin deficiency & POMC & $\begin{array}{l}\text { Severe early-onset hyperphagic } \\
\text { obesity, red hair }\end{array}$ \\
$\begin{array}{l}\text { Proprotein convertase 1 } \\
\text { mutation }\end{array}$ & PCSK1 & $\begin{array}{l}\text { Hypoglycemia, malabsorption, } \\
\text { gonadotropin deficiency }\end{array}$ \\
\hline
\end{tabular}

ACTH, adrenocorticotropic hormone; $\mathrm{CAH}$, congenital adrenal hyperplasia; CRH, corticotropin-releasing hormone; DSD, disorder of sex development; NK, natural killer.

glucocorticoids when under physiological stress. Adrenal crisis can also occur as the initial clinical presentation of AI. Appropriate management requires immediate recognition of the clinical signs, symptoms and biochemical profile of AI and the triggers for adrenal crisis. Therefore, primary care, urgent care and ED providers must be trained to recognize the diverse clinical circumstances in which $\mathrm{AI}$ can occur. In children with known AI, parents and care providers must be familiar with the administration of maintenance and stress dose glucocorticoid therapy to prevent adrenal crises. This can be facilitated by providing the family with a written Adrenal Insufficiency Action Plan and Emergency Care Letter. Currently, hydrocortisone, or an equivalent synthetic glucocorticoid, is not available on most ambulances for emergency administration by EMS personnel. In addition, EMT training on the use of patient's home medication is not widely employed. Both of these situations can lead to life-threatening delays in providing appropriate therapy to prevent or treat adrenal crises.

AI is a significant cause of morbidity and mortality in children ${ }^{1-3}$ with an annual estimated incidence of adrenal crisis of 5-10 episodes per 100 patient-years, with increasing rates in some countries. ${ }^{4}$ One in every 200 episodes of adrenal crisis results in death. ${ }^{5}$ Therefore, the goal of this working group was to raise awareness on the importance of early recognition and provide guidance on the emergency management of $\mathrm{AI}$ in children during illnesses, particularly in the outpatient, EMS and ED settings.

\section{ETIOLOGY}

$\mathrm{AI}$ is characterized by impaired adrenal synthesis of glucocorticoids. When reduced production of mineralocorticoid (aldosterone) is present it is associated with hyponatremia due to salt-wasting and reciprocal hyperkalemia. AI can be categorized as primary, where the defect is in the adrenal gland, or secondary (central), where the defect is due to hypothalamic and/or pituitary dysfunction. In the central forms deficient secretion of ACTH leads to atrophy of the zona fasciculata in the adrenal cortex (the source of glucocorticoids); mineralocorticoid production by the zona glomerulosa is preserved because the renin-angiotensin system is intact.

The most common cause of primary AI in children is congenital adrenal hyperplasia (CAH), the leading cause of atypical genitalia in female newborns. Less common causes of primary AI include autoimmune adrenalitis (isolated or part of autoimmune polyglandular syndromes), infections, bilateral adrenal hemorrhage, and various genetic 


\section{Box 1 Acquired causes of adrenal insufficiency}

\section{PrimaryPrimary}

- Autoimmune adrenalitis (Addison disease)

- Isolated.

- Autoimmune polyendocrinopathy type 1.

- Autoimmune polyendocrinopathy type 2 .

Bilateral hemorrhage/infarction

- Trauma.

- Waterhouse-Friderichsen syndrome.

- Anticoagulation.

- Drug effect: mifepristone, aminoglutethimide, mitotane, ketoconazole, etomidate, metyrapone, rifampin, phenytoin, barbiturates, tyrosine kinase inhibitors (eg, sunitinib)

- Infection

- Viral: HIV, cytomegalovirus.

- Fungal: coccidioidomycosis, histoplasmosis, blastomycosis, cryptococcosis.

- Mycobacterial: tuberculosis.

- Amebic.

- Infiltrative

- Hemochromatosis, histiocytosis, sarcoidosis, amyloidosis, neoplasm.

- Surgery: bilateral adrenalectomy

Secondary: hypothalamusSecondary: hypothalamus

- Corticosteroid withdrawal after prolonged administration (inhaled, intranasal, oral, rectal, intravenous and topical).

- Corticosteroid withdrawal after parenteral administration of high doses of potent and longer acting preparations (intramuscular, intradermal and intraarticular routes).

- Drug effect: megestrol, mitotane, medroxyprogesterone, rifampin, phenytoin, barbiturates, tyrosine kinase inhibitors (eg, sunitinib).

- Inflammatory disorders.

- Trauma.

- Radiation therapy.

- Surgery.

- Tumors: craniopharyngioma, germinoma.

- Infiltrative disease: sarcoidosis, histiocytosis.

Secondary: pituitarySecondary: pituitary

- Corticosteroid withdrawal after prolonged administration.

- Trauma.

- Tumor: craniopharyngioma.

- Radiation therapy.

- Lymphocytic hypophysitis.

syndromes including $\mathrm{X}$ linked adrenoleukodystrophy ${ }^{6-8}$ (see table 1 and box 1 ).

The most common cause of secondary (central) AI is low ACTH due to iatrogenic suppression of the pituitary corticotrophs by prolonged use of supraphysiological doses of oral glucocorticoids typically prescribed for the treatment of medical conditions including but not limited to asthma, hematologic/oncologic conditions, inflammatory bowel disorders, rheumatologic conditions, nephrotic syndrome, neurologic disorders, postneurosurgical procedures, and hematopoietic and solid organ transplants. Glucocorticoids administered by intra-articular, topical, intradermal, and inhaled routes may also suppress the hypothalamicpituitary-adrenal (HPA) axis. ${ }^{910}$ Other medications, such as megestrol acetate, ketoconazole, and mifepristone, also impair adrenal function via direct and indirect mechanisms. Less common secondary causes of ACTH deficiency involving the pituitary and hypothalamus include tumors, radiation exposure, congenital anomalies, and specific gene defects (table 1 and box 1). Inherited forms of ACTH deficiency are usually associated with additional pituitary hormone deficiencies.

The magnitude of suppression of the HPA axis in relation to dose, duration, and type of glucocorticoid therapy can vary among individuals due to variability in glucocorticoid pharmacokinetics and interindividual glucocorticoid receptor sensitivity. ${ }^{11}$ Generally, the HPA axis recovers rapidly when the duration of glucocorticoid treatment is short, that is, less than 7-10 days, even when high doses are used. In these circumstances, it is appropriate to discontinue glucocorticoids abruptly. However, if the duration of therapy is 3 weeks or longer, it is recommended that the glucocorticoid dose be tapered gradually to avoid precipitating symptoms of steroid dependence and/or AI. ${ }^{12}$ Protracted use of supraphysiological glucocorticoid doses may result in severe adrenal gland atrophy and prolonged AI lasting up to 34 weeks requiring glucocorticoid tapering to be extended over many months. ${ }^{1314}$

A Cochrane review of 8 studies of 9218 children with acute lymphoblastic leukemia treated with prolonged courses of supraphysiological doses of long-acting glucocorticoids, including dexamethasone, prednisolone and prednisone, revealed that AI occurred in nearly all children in the first days after discontinuation of glucocorticoids. ${ }^{13}$ However, the precise duration of glucocorticoid therapy and tapering protocol were not reported in the majority of the studies. While most of the children recovered within several weeks, a few children had prolonged AI lasting up to 34 weeks. Fluconazole was noted in one of these studies to possibly prolong the duration of AI while another study identified stress and infection to be risk factors. ${ }^{15}$

A meta-analysis examining the role of inhaled corticosteroids (ICS) in suppression of the HPA axis noted no AI with ICH doses of $\leq 400 \mathrm{mcg}$ of beclomethasone dipropionate daily. ${ }^{9}{ }^{16}$ However, subsequent reports have noted HPA axis suppression at lower ICS doses. ${ }^{37}$ Since the bioavailability and bioequivalence of ICS preparations vary along with individual glucocorticoid sensitivity, it is difficult to identify a threshold dose for all ICS that will cause HPA axis suppression. ${ }^{18}$ Therefore, it is important to recognize chronic ICS therapy as a risk factor for AI. A study of infants with hemangiomas treated with high-dose glucocorticoid therapy for 12-26 weeks demonstrated the return of normal circadian response in salivary cortisol levels within 6 weeks and normal response to administration of low-dose ACTH stimulation by 12 weeks after stopping treatment. ${ }^{14}$

During the process of recovery from HPA suppression, physiological circadian secretion of cortisol may recover before return of the ability of the hypothalamus to respond to stress. ${ }^{19}$ Therefore, a patient may have a normal 8:00 AM cortisol, but still be unable to show an appropriate serum cortisol response to stress. ${ }^{2021}$ The wide variability in 
timing of recovery of the HPA axis after discontinuation of glucocorticoid exposure emphasizes the need for clinicians to be aware of clinical scenarios with an increased risk of AI.

\section{DIAGNOSIS OF ACUTE AI Triggers}

Diagnosis of AI can be challenging as the clinical signs are not specific and may progress insidiously over time. Adrenal crisis can be precipitated by acute illness, physical stress or injury requiring increased cortisol production above basal needs in the setting of normal adrenal function. In addition, induction of anesthesia and surgery can precipitate acute AI.

\section{Clinical signs}

Acute AI can present with fatigue, weakness, tachycardia, hypotension, dizziness, nausea, vomiting, abdominal pain, diaphoresis and seizures. If unrecognized and not treated quickly, AI can progress to coma and death. ${ }^{3} 69$ 22-25 Prolonged cholestatic jaundice, failure to gain weight and hypoglycemia may be the presenting clinical features in neonates and infants. Micropenis, bilateral cryptorchidism and, rarely, central diabetes insipidus may also be present in neonates who have AI due to panhypopituitarism. Individuals with primary AI may have hyperpigmentation of the skin (particularly creases, folds and scars), gums and buccal mucosa.

\section{General biochemistry}

In acute AI, hyponatremia is the most consistent biochemical finding. ${ }^{12}$ Hyperkalemia is present in primary, but not secondary AI, and can be associated with hypercalcemia and metabolic acidosis. Hypoglycemia is more frequent in neonates and infants regardless of the type of AI. Other findings include normocytic anemia, lymphocytosis and eosinophilia.

\section{Hormonal measurements and provocative testing}

The diagnosis of primary AI is suggested by blood tests preferably performed at 8:00 AM that show an ACTH level greater than $100 \mathrm{pg} / \mathrm{mL}$ and a cortisol level less than 10 $\mathrm{mcg} / \mathrm{dL}^{1}$ or by an ACTH level that is twofold greater than the upper limit of the normal range and a cortisol level less than $5 \mathrm{mcg} / \mathrm{dL} .^{8}{ }^{26}$ Low serum aldosterone with elevated plasma renin activity is the hallmark of mineralocorticoid deficiency. Secondary AI is associated with low levels of both cortisol and ACTH. An 8:00 AM serum cortisol level of $\leq 3 \mathrm{mcg} / \mathrm{dL}$ is highly suggestive of the diagnosis whereas a cortisol value of $\geq 18 \mathrm{mcg} / \mathrm{dL}$ essentially excludes $\mathrm{AI} .{ }^{1}$ If $\mathrm{AI}$ is suspected during an acute illness, a random cortisol and ACTH should be obtained prior to initiating glucocorticoid therapy. A serum cortisol concentration less than $18 \mathrm{mcg} / \mathrm{dL}$ during acute illness can be indicative of AI. ${ }^{12}$ Cortisol and ACTH levels may be difficult to interpret in neonates and infants as circadian pattern of secretion does not appear until 4 months ${ }^{27}$ and cortisol-binding globulin is low causing low total, but not free, serum cortisol.

If levels of plasma ACTH and/or serum cortisol are equivocal, dynamic testing of adrenal function with cosyntropin should be done. Typically a high-dose cosyntropin stimulation test is preferred when primary AI is suspected (usual dose is $15 \mathrm{mcg} / \mathrm{kg}$ in neonates, $125 \mathrm{mcg}$ in infants $<2$ years, and $250 \mathrm{mcg}$ in older children). In secondary AI, dynamic testing with either high or low-dose cosyntropin $(1 \mathrm{mcg})$ has been used for evaluation of the HPA axis. Regardless of the cosyntropin dose used, a serum cortisol level $>18 \mathrm{mcg} /$ $\mathrm{dL}$ rules out AI. The low-dose protocol is not universally accepted primarily due to technical factors influencing the test results. A dose of $1 \mathrm{mcg}$ cosyntropin requires preparation by the person carrying out the test. Also, the prepared dilution should be given intravenously without using a catheter made of 'fluorinated ethylene propylene' plastic to which the cosyntropin binds. ${ }^{12} 2628-30$

\section{TREATMENT}

There is limited empirical evidence to guide the optimal glucocorticoid stress-dosing of children and adolescents who have AI. While the debate about what constitutes physiological stress is unresolved, several situations are generally accepted as significant stress including: fever $>38^{\circ} \mathrm{C}$ $\left(100.4^{\circ} \mathrm{F}\right)$, intercurrent illness with emesis, prolonged or voluminous diarrhea, infectious disease requiring antibiotics, acute trauma requiring medical intervention (eg, fracture) and anesthesia and associated surgical procedures. Guidelines on cortisol requirement in times of physiological stress have been based on the general acceptance that conditions of maximal stress increase the serum cortisol levels by 2-3 times. ${ }^{152631}$ Treatment recommendations below are based on recent literature on glucocorticoid replacement therapy.

\section{OUTPATIENT PREVENTION OF ACUTE AI General pediatricians and endocrinologists}

Following the diagnosis of AI, comprehensive educational outreach should include the family and caregivers, the primary care physician, and the local emergency care providers regarding the signs, symptoms and treatment of cortisol deficiency to prevent adrenal crises. Electronic medical records (EMR) may be used to flag patients with known or at high risk for AI to increase provider attention. ${ }^{3233}$

The first step in preventing acute $\mathrm{AI}$ is maintenance glucocorticoid replacement therapy. Maintenance dosing of glucocorticoid is based on the secretory rate of cortisol which has been reported to be $5-8 \mathrm{mg} / \mathrm{m}^{2} / \mathrm{d}$ in healthy controls. ${ }^{34} 35$ For primary AI other than $\mathrm{CAH}$, hydrocortisone at $8-12 \mathrm{mg} / \mathrm{m}^{2} / \mathrm{d}$ in 3 divided doses is recommended. ${ }^{126}$ In $\mathrm{CAH}$, the consensus dosing is $10-15 \mathrm{mg} / \mathrm{m}^{2} / \mathrm{d}{ }^{36}$ Patients with secondary AI may be maintained on a lower dose. ${ }^{137}$

A challenge with hydrocortisone therapy is its short median elimination half-life, especially in children with CAH (58 minutes (range: 41-105 minutes)) allowing most of the hydrocortisone dose to be eliminated from the body within 4-7 hours. ${ }^{1138}$ To prevent alternating periods of hypocortisolemia and hypercortisolemia throughout each day in children with AI, hydrocortisone should be administered in at least 3 divided doses. A 6-hour pharmacokinetic/pharmacodynamic study in children with $\mathrm{CAH}$ showed that maximum suppression of adrenal steroids (17-hydroxyprogesterone and androstenedione) occurs 3-4hours after hydrocortisone dose and that adrenal steroids rebounded toward elevated baseline concentrations 
by the end of 6 hours. ${ }^{11}$ This suggests that the elimination half-life of cortisol is more relevant to adrenal steroid suppression than the biological or pharmacological half-life of cortisol (8 hours).$^{39}$ Because of hydrocortisone pharmacokinetic properties and in order to mimic physiological circadian cortisol profiles, the highest hydrocortisone dose should be given in the morning. ${ }^{113140}$

Long-acting glucocorticoids such as dexamethasone, prednisone and prednisolone are not recommended for maintenance glucocorticoid therapy in growing children. ${ }^{26364142}$ The use of long-acting glucocorticoids, such as dexamethasone, in treatment of initial adrenal crisis will prevent the provider from performing an ACTH stimulation test during the initial hospitalization to establish the definitive diagnosis. Prednisolone and dexamethasone are 15 -fold and 80-100-fold more potent, respectively, than hydrocortisone in terms of growth suppression. ${ }^{42}{ }^{43}$ A modified-release formulation of hydrocortisone (Chronocort) given twice daily has been studied in adults with $\mathrm{CAH}^{44}$ but failed to meet the phase 3 trial primary objective confirming its superiority over conventional treatment. ${ }^{45}$

During infancy to early childhood, smaller doses and incremental adjustments are required to avoid the adverse effects of glucocorticoid excess including obesity, hypertension, impaired growth, osteoporosis and insulin resistance. However, lack of availability of tablets in strengths lower than $5 \mathrm{mg}$ makes dosing of infants difficult and less precise. Currently there is no commercially available liquid formulation that provides dosing in $0.1 \mathrm{mg}$ increments since withdrawal of hydrocortisone cypionate suspension in $2001 .^{46}$ Quartering $5 \mathrm{mg}(6.5 \mathrm{~mm})$ or $10 \mathrm{mg}(8 \mathrm{~mm})$ hydrocortisone tablets can lead to inconsistent cortisol levels and result in either undertreatment or overtreatment due to unacceptable dose variability. ${ }^{47}$ Crushed, weighed hydrocortisone capsules from a compounding pharmacy may also lead to inconsistent cortisol levels and overtreatment. ${ }^{49}{ }^{50}$ Alcoholfree hydrocortisone oral suspension $(2 \mathrm{mg} / \mathrm{mL})$ prepared from $10 \mathrm{mg}$ tablets provides good dose repeatability when shaken before use and was stable for 90 days when stored in either a bottle or syringe at either $4^{\circ} \mathrm{C}$ or $25^{\circ} \mathrm{C} .{ }^{51} \mathrm{~A}$ pharmacokinetic study in children with $\mathrm{CAH}$ showed no difference in the extent or rate of hydrocortisone absorption between alcohol-free hydrocortisone suspension prepared from $10 \mathrm{mg}$ tablets by a compounding pharmacy and hydrocortisone tablets. ${ }^{52}$ Future studies may encourage the development of a Food and Drug Administration (FDA)-approved commercially available alcohol-free hydrocortisone suspension. Uncoated minitablets of $2.5 \mathrm{mg}(3 \mathrm{~mm})$ could also be an alternative. ${ }^{485354}$ Multiparticulate hydrocortisone granules (Alkindi) with doses of 0.5, 1, 2 and $5 \mathrm{mg}$ have been recently licensed in Europe. ${ }^{55}$

In this guideline, we outline an Adrenal Insufficiency Action Plan (figure 2) and an Adrenal Insufficiency Instructions for Emergency Room Staff (figure 3), a stepwise approach to hydrocortisone dosing during illness similar to the extremely successful Asthma Action Plan. ${ }^{56}$ Our goal is to provide clear guidance for caregivers, primary care physicians, urgent care and emergency providers for appropriate stress dosing of hydrocortisone or its equivalent in children with known AI during illness and surgical procedures to prevent and treat adrenal crisis. The Adrenal Insufficiency Action Plan provides instructions for oral stress dosing with hydrocortisone (double or triple the daily dose given every 6-8 hours) and injectable hydrocortisone dosing when unable to take oral stress dose. All children with AI should be provided with an individualized care plan (Adrenal Insufficiency Action Plan and/or medical letter, see figures 1, 2 and 3), which could be made available in EMRs. The use of such tools has been shown to improve patient education regarding management of physiological stress in outpatient settings. ${ }^{3233}$ In addition, children with AI need a medical alert identification for EMS personnel.

All caregivers should be educated on the use of injectable intramuscular hydrocortisone sodium succinate in the event of emesis or an altered state of consciousness. As administration of intramuscular hydrocortisone sodium succinate requires multiple preinjection steps, a prefilled, single-use autoinjector (ZENEO Hydrocortisone) is in development in France. The use of rectal hydrocortisone suppositories in the management of adrenal crisis may not achieve desired cortisol concentrations. ${ }^{57}$

\section{EMS and hospital transport treatment of acute AI}

Children with known AI requiring EMS transport should receive an intramuscular injection of potentially life-saving hydrocortisone sodium succinate as soon as possible by the family/caretaker or by EMS providers either using the family's supply or having hydrocortisone sodium succinate available in the EMS vehicles, including mobile care units. Prolonged transportation times for patients living in rural areas may delay administration for several hours further underscoring the importance of EMS access to hydrocortisone sodium succinate. Clearly, local and state regulations and provider practice scope need to be considered by the agency's medical director prior to implementation. In addition, we need to advocate that local and state regulations be updated to support the emergent administration of hydrocortisone sodium succinate by EMS personnel outside the hospital to individuals with known AI. A small number of states and provinces have legislation allowing administration of patient-carried medication and have EMS glucocorticoid protocols in place. ${ }^{58}{ }^{59}$ In this emergency setting, hydrocortisone sodium succinate should be administered at $50-100 \mathrm{mg} / \mathrm{m}^{2}$ intramuscularly $(5-10$ times the physiologic cortisol secretory rate). ${ }^{152660}$ The Endocrine Society Clinical Practice Guideline suggests stress doses of hydrocortisone sodium succinate based on patient's age: children $\leq 3$ years: $25 \mathrm{mg}$; school-age children ( $>3$ and $<12$ years): $50 \mathrm{mg}$; and older children and adolescents $(\geq 12$ years): $100 \mathrm{mg}$ as an initial stress dose. ${ }^{266162}$ We recommend using the $100 \mathrm{mg} / 2 \mathrm{~mL}$ vial as its dilution is simple if smaller doses are needed. Finally, we also recommend adding age-related hydrocortisone sodium succinate dosing to weight-based dosing tapes used in emergency care of children, as their use is ubiquitous. ${ }^{63}$

Regarding other glucocorticoids, dexamethasone sodium phosphate $\left(1.5-2 \mathrm{mg} / \mathrm{m}^{2} / \text { dose }\right)^{1}$ has been available in some EMS settings and used in secondary AI. However, it is not suitable for treatment of salt-wasting adrenal crisis in primary $\mathrm{AI}$ because it has no mineralocorticoid effect. Methylprednisolone sodium succinate $\left(10-25 \mathrm{mg} / \mathrm{m}^{2} /\right.$ dose intramuscular) may be used to treat adrenal crisis although it has less mineralocorticoid activity than hydrocortisone. ${ }^{64}$ 


\section{ADRENAL INSUFFICIENCY EMERGENCY CARE LETTER "ADRENAL INSUFFICIENCY ACTION PLAN"}

Name Doe-Smith, Jane DOB 01/01/01

Adrenal insufficiency is a condition that results in inadequate amounts of cortisol. Cortisol helps maintain normal blood pressure, cardiovascular function, and blood glucose (sugar) levels, especially during injury and illness.

Jane is at risk for adrenal crisis during illness (such as fever, diarrhea, vomiting), injury, and surgery. Jane MUST receive extra cortisol (glucocorticoid) during these times to avoid severe complications, including death.

This letter is not exhaustive and is not a substitute for contact with the Pediatric Endocrinology physician on call available 24 hours/day (phone \#\#). Please follow the instructions and contact us immediately.

\section{REGULAR HOME TREATMENT}

As part of her regular home treatment, Jane Doe-Smith receives cortisol replacement in the form of hydrocortisone tablets (5 mg / $10 \mathrm{mg}$ ). Her total daily hydrocortisone dose is \#\# $\mathrm{mg}$. This is given as \#\# $\mathrm{mg}$ at \# am, \#\# $\mathrm{mg}$ at \# pm, and \#\# $\mathrm{mg}$ at \#pm.

\section{SICK DAY HOME TREATMENT}

For fever $>38^{\circ} \mathrm{C}\left(100.4^{\circ} \mathrm{F}\right)$, diarrhea, vomiting, or severe injury, please triple her total daily dose divided into 4 doses (\#\# mg every 6 hours) until symptoms have resolved. Please contact the on-call Pediatric Endocrinology physician (phone \#\#\#).

If Jane cannot tolerate oral hydrocortisone or is unconscious, please give an intramuscular injection of hydrocortisone sodium succinate (Solu-Cortef( ) according to the table below. Next, contact the on-call Pediatric Endocrinology physician (phone \#\#) and go to the nearest emergency department.

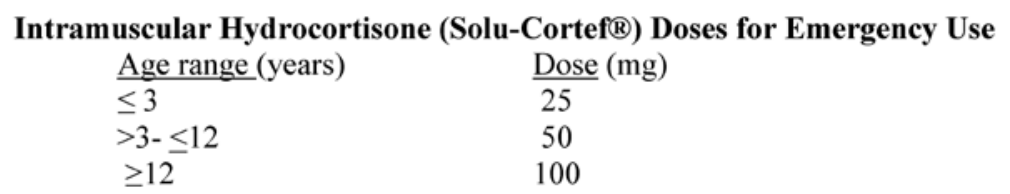

\section{EMERGENCY ROOM INSTRUCTIONS}

Room Jane immediately, monitor vital signs closely, and start an IV. Administer IV hydrocortisone \#\# mg every 6 hours. If unable to place IV in 15 minutes, please give hydrocortisone dose IM. Administer IV D5 NS at $1 \frac{1}{2}$ to 2 times maintenance with appropriate electrolytes. Collect electrolytes and blood glucose.

Please contact the on-call Pediatric Endocrinology physician (phone \#\#) immediately for further instructions. If Jane does not respond to above intervention, more intensive management may be required, including transfer to tertiary care.

\section{ADDITIONAL INSTRUCTIONS FOR MAJOR and MINOR SURGERIES}

Please call the Pediatric Endocrinology physician (phone \#\#) immediately when a decision to go to surgery is made. General guidelines for emergency surgery are as follows.

Major Surgery: Hydrocortisone $100 \mathrm{mg} / \mathrm{m}^{2} / \mathrm{dose}$ (\#\# mg IV every 6 hours during the length of the procedure with the first dose being administered at the induction of anesthesia. For the 24 hours following the procedure, give $100 \mathrm{mg} / \mathrm{m}^{2} / \mathrm{day}$ (\#\# mg IV every 6 hours). On the second day following the procedure, decrease hydrocortisone to $50 \mathrm{mg} / \mathrm{m}^{2} / 24 \mathrm{hour}$ (\#\# mg every 6 hours) and transition to oral hydrocortisone when possible. On the third day after the procedure, decrease to $25 \mathrm{mg} / \mathrm{m}^{2} / 24$ hour (\#\# mg of hydrocortisone every 6 hours). If stable after this, transition back to usual hydrocortisone dose. While on intravenous (IV) fluids, the patient should receive D5 NS at $1 \frac{1}{2}$ to 2 times maintenance. After surgery, IV fluids can be titrated to her oral intake as tolerated.

Minor Surgery: $50 \mathrm{mg} / \mathrm{m}^{2} /$ dose (\#\# mg) IM) 1 hour prior to procedure or $50 \mathrm{mg} / \mathrm{m}^{2} / \mathrm{dose}$ (\#\# mg IV during the procedure. Depending on the length of fasting or duration of the procedure, IV fluids should be started at D5 NS at $1 \frac{1 / 2}{2}$ to 2 times maintenance.

Figure 1 Adrenal Insufficiency Emergency Care Letter.

\section{ED TREATMENT OF ADRENAL CRISIS}

Vague and non-specific symptoms of AI make the diagnosis of adrenal crisis easily overlooked in the ED triage process. Hypotension and hypoglycemia can develop suddenly in the ED, ${ }^{65}$ even after normal triage assessments. Providers must exercise a high index of suspicion for adrenal crisis in any child who is at risk of AI (table 1 and box 1). In cases of known AI the ED letter (figure 1, modified from ref ${ }^{66}$ ) or Adrenal Insufficiency Action Plan should be given to triage personnel on arrival to the ED to speed the process.

The initial stress dose of hydrocortisone sodium succinate given by family, EMS, or in ED should be followed by $50-100 \mathrm{mg} / \mathrm{m}^{2} / \mathrm{d}$ divided into 4 doses given every 6 hours or given by continuous infusion. ${ }^{152660}$ In the ED, intravenous 
ADRENAL INSUFFICIENCY ACTION PLAN (INCLUDING SICK DAY \& EMERGENCY MANAGEMENT)

Date: (should be revised annually)

Name:

Age__ years__ months Weight

$\mathrm{kg}$ BSA $m^{2}$

Cause of adrenal insufficiency: CAH / Addison disease / Hypopituitarism / latrogenic adrenal insufficiency / Other

\begin{tabular}{|c|c|}
\hline SITUATION & INSTRUCTIONS \\
\hline $\begin{array}{l}\text { MAINTENANCE (USUAL) DOSES } \\
\text { - Take these doses on a daily basis when well }\end{array}$ & 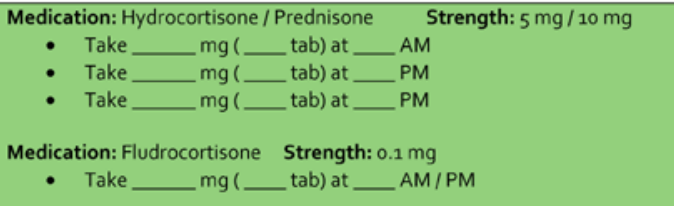 \\
\hline $\begin{array}{l}\text { SICK DAY MANAGEMENT ("Stress Dosing") } \\
\text { - With any physical stress such as infections or injuries, the } \\
\text { body needs higher amounts of hydrocortisone. } \\
\text { - In the event of fever (above } 38 \text { Celsius or } 100.4 \text { Fahrenheit), } \\
\text { infection that requires antibiotics, vomiting, diarrhea, or } \\
\text { fracture, use the higher doses for } 24 \text { to } 48 \text { hours. } \\
\text { - Resume usual (maintenance) doses of hydrocortisone when } \\
\text { fever/stress has resolved. }\end{array}$ & $\begin{array}{l}\text { Medication: Hydrocortisone Strength: } 5 \mathrm{mg} / 10 \mathrm{mg} \\
\text { - Take_ } \quad \text { Stress Dose is typically double or triple usual daily dose } \\
\text { Call Endocrinology Team }\end{array}$ \\
\hline $\begin{array}{l}\text { EMERGENCY MANAGEMENT (Solu-Cortef Injection) } \\
\text { - When unable to tolerate oral medication, hydrocortisone by } \\
\text { injection will be necessary } \\
\text { - In the event of severe illness, trauma, inability to tolerate oral } \\
\text { hydrocortisone, unconsciousness, or repeated vomiting, } \\
\text { administer Solu-Cortef by intramuscular (IM)injection } \\
\text { CHILD WILL NEED URGENT MEDICAL EVALUATION \& IV FLUIDS }\end{array}$ & 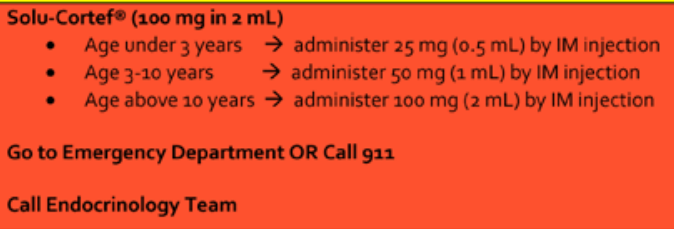 \\
\hline $\begin{array}{l}\text { PREPARATION FOR SURGERY } \\
\text { - The stress of surgery and recover from it necessitates higher } \\
\text { doses of hydrocortisone during and } 1-3 \text { days after surgery. } \\
\text { - This requires team approach among the healthcare } \\
\text { professionals managing the surgery and post-operative care. }\end{array}$ & $\begin{array}{l}\text { Make the surgeon (or dentist) and anesthesiologist aware } \\
\text { - Diagnosis of Adrenal Insufficiency and medication doses } \\
\text { Surgical team and endocrinologist should communicate with each other } \\
\text { - Plan well before the date of surgery } \\
\text { - Decide on hydrocortisone doses before and after surgery }\end{array}$ \\
\hline
\end{tabular}

PEDIATRIC ENDOCRINOLOGY TEAM CONTACT INFORMATION

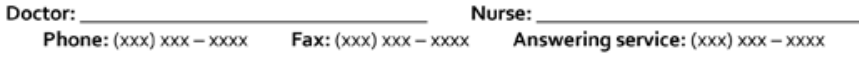

Figure 2 Adrenal Insufficiency Action Plan.

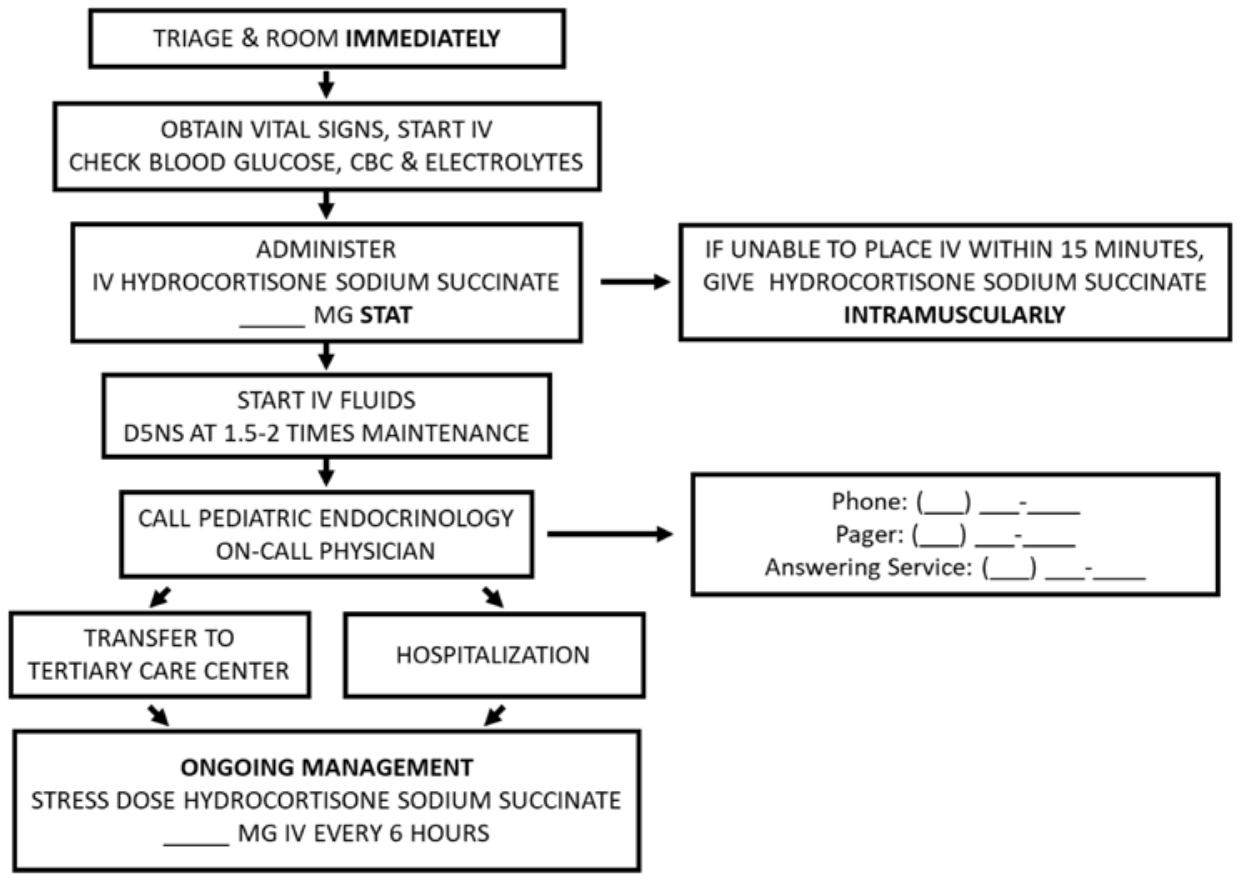

Figure 3 Adrenal Insufficiency Instructions for Emergency Room Staff. CBC, complete blood count; IV, intravenous. 
dosing is preferred for the initial stress dose, however, if an intravenous catheter cannot be placed quickly, the initial dose should be given intramuscularly. Ongoing stress doses are typically given parenterally for the first $24-48$ hours and then transitioned to oral dosing if feasible. Because hydrocortisone sodium succinate in high doses has mineralocorticoid effect, no fludrocortisone is needed while the patient receives intravenous fluids and stress doses of hydrocortisone.

Appropriate evaluation (as described above) should include biochemical documentation of the AI (serum cortisol and plasma ACTH levels), assessment of hydration and acid-base status, and investigation of an underlying precipitant. Ideally, a blood sample should be collected prior to administration of hydrocortisone sodium succinate, especially for patients with a suspected new diagnosis of AI; however, treatment should NOT be delayed if obtaining a blood sample proves difficult.

\section{Summary of recommendations}

- Patients with known Al and their families should be provided an Adrenal Insufficiency Action Plan, including maintenance hydrocortisone dose, stress dose for hydrocortisone (both oral and intramuscular/ intravenous) and contact information for their endocrinologist. They should be instructed to keep this with them at all times and to provide it immediately to EMS providers and triage personnel in urgent care and emergency departments.

- All patients with known Al should carry medical alert identification indicating the diagnosis and glucocorticoid dependency.

- Families should be educated to use intramuscular hydrocortisone sodium succinate for emergency situations.

- Development of FDA-approved hydrocortisone formulations that allow for smaller, more precise dosing in infants and young children with Al.

- Awareness of the multiple potential causes of Al, including glucocorticoid therapy for other conditions, and a high index of suspicion for $\mathrm{Al}$ in children presenting with hypoglycemia, hyponatremia and hypotension is necessary to identify new cases of Al and urgently treat adrenal crises.

- Acute adrenal crisis requires rapid treatment of hypovolemia, hyponatremia, and hypoglycemia with normal saline and $10 \%$ dextrose intravenously in addition to stress dose hydrocortisone administration.

- Hydrocortisone should be added to weight-based dosing tapes.

- Emergency medical transport services should be aware of and emphasize emergency administration of stress dose hydrocortisone sodium succinate within constraints of their systems. Advocacy efforts to increase the availability of stress dose hydrocortisone sodium succinate (Solu-Cortef Act-o-Vial, preferably $100 \mathrm{mg} / 2 \mathrm{~mL}$ ) during emergency medical transport care, including mobile care units, are highly encouraged.
In an acute adrenal crisis, hypovolemia should be rapidly reversed with a $20 \mathrm{~mL} / \mathrm{kg}$ bolus of isotonic solution, preferably normal saline. Hypoglycemia should be treated with a $2.5 \mathrm{~mL} / \mathrm{kg}$ bolus of $10 \%$ dextrose solution and repeated if the response is not adequate.

\section{CONCLUSIONS}

Patients with AI (primary or secondary) may present to EMS personnel or the ED in an acute life-threatening crisis needing prompt and effective management to avoid severe consequences. This document offers evidence and consensus-based expert guidelines for most effective management of $\mathrm{AI}$ in the emergent scenario. A high index of suspicion needs to be maintained in all patients at risk for acute adrenal crisis.

\section{Author affiliations}

'Department of Pediatrics, University of Minnesota Masonic Children's Hospital, Minneapolis, Minnesota, USA

${ }^{2}$ Department of Pediatrics, Nationwide Children's Hospital, Columbus, Ohio, USA

${ }^{3}$ Department of Pediatrics, Children's Hospital of Los Angeles, Los Angeles, California, USA

${ }^{4}$ Department of Pediatrics, MedStar Georgetown University Hospital, Washington, DC, USA

${ }^{5}$ Department of Pediatrics, Le Bonheur Children's Hospital, Memphis, Tennessee, USA

${ }^{6}$ Department of Pediatrics, Massachusetts General Hospital, Boston, Massachusetts, USA

${ }^{7}$ Department of Pediatrics, UH Rainbow Babies and Children's Hospital, Cleveland, Ohio, USA

${ }^{8}$ Department of Pediatrics and Child Health, University of Manitoba, Winnipeg, Manitoba, Canada

Contributors All the authors have participated in the concept and design, analysis and interpretation of data, drafting or revising of the manuscript, have approved the manuscript as submitted, and have agreed to be accountable for all aspects of the work.

Funding This research received no specific grant from any funding agency in the public, commercial or not-for-profit sectors.

Competing interests BSM is a consultant for AbbVie, Ascendis, Ferring, Novo Nordisk, Pfizer, Sandoz, Soleno and Tolmar and has received research support from Alexion, Ascendis, BioMarin, Endo Pharmaceuticals, Genentech, Genzyme, Novo Nordisk, Opko, Sandoz, Sangamo, Shire, Tolmar and Versartis. MK received grant support from T1D Exchange Quality Improvement Collaborative. MG is a consultant for Spruce Biosciences, Millendo, Pfizer, and BridgeBio. KS receives research support from the DHHS Federal Food and Drug Administration, NIH National Cancer Institute, March of Dimes, National Science Foundation, Spruce Biosciences, Alexion and Neurocrine.

Patient consent for publication Not required.

Provenance and peer review Not commissioned; externally peer reviewed.

Open access This is an open access article distributed in accordance with the Creative Commons Attribution Non Commercial (CC BY-NC 4.0) license, which permits others to distribute, remix, adapt, build upon this work noncommercially, and license their derivative works on different terms, provided the original work is properly cited, an indication of whether changes were made, and the use is non-commercial. See: http://creativecommons.org/ licenses/by-nc/4.0/.

ORCID iD

Bradley S Miller http://orcid.org/0000-0003-3663-5473

\section{REFERENCES}

1 Shulman DI, Palmert MR, Kemp SF, et al. Lawson Wilkins Drug and Therapeutics Committee. Adrenal insufficiency: still a cause of morbidity and death in childhood. Pediatrics 2007;119:e484-e494. 
2 Ahmet A, Kim H, Spier S. Adrenal suppression: A practical guide to the screening and management of this under-recognized complication of inhaled corticosteroid therapy. Allergy, Asthma \& Clinical Immunology 2011;7:13.

3 Todd GRG, et al. Survey of adrenal crisis associated with inhaled corticosteroids in the United Kingdom. Arch Dis Child 2002;87:457-61.

4 Rushworth RL, Torpy DJ. Adrenal insufficiency in australia: Is it possible that the use of lower dose, short-acting glucocorticoids has increased the risk of adrenal crises? Horm Metab Res 2015;47:427-32.

5 Allolio B. Extensive expertise in endocrinology. Adrenal crisis. Eur J Endocrinol 2015;172:R115-R124.

6 Charmandari E, Nicolaides NC, Chrousos GP. Adrenal insufficiency. The Lancet 2014;383:2152-67

7 Flück CE. Mechanisms in endocrinology: Update on pathogenesis of primary adrenal insufficiency: beyond steroid enzyme deficiency and autoimmune adrenal destruction. Eur J Endocrinol 2017;177:R99-R111.

8 Regelmann MO, Kamboj MK, Miller BS, et al. Adrenoleukodystrophy: Guidance for adrenal surveillance in males identified by newborn screen. J Clin Endocrinol Metab 2018;103:4324-31.

9 Kapadia CR, Nebesio TD, Myers SE, et al. Endocrine effects of inhaled corticosteroids in children. JAMA Pediatr 2016;170:163-70.

10 Finken MJ, Mul D. Cushing's syndrome and adrenal insufficiency after intradermal triamcinolone acetonide for keloid scars. Eur J Pediatr 2010;169:1147-9.

11 Sarafoglou K, Zimmerman CL, Gonzalez-Bolanos MT, et al. Interrelationships among cortisol, 17-hydroxyprogesterone, and androstenendione exposures in the management of children with congenital adrenal hyperplasia. J Investig Med 2015;63:35-41.

12 Chanson P, Guignat L, Goichot B, et al. Group 2: Adrenal insufficiency: screening methods and confirmation of diagnosis. Ann Endocrinol 2017;78:495-511.

13 Rensen N, Gemke RJ, van Dalen EC, et al. Hypothalamic-pituitary-adrenal (HPA) axis suppression after treatment with glucocorticoid therapy for childhood acute lymphoblastic leukaemia. Cochrane Database Syst Rev 2017;11:CD008727

14 Mendoza-Cruz AC, Wargon O, Adams S, et al. Hypothalamic-pituitary-adrenal axis recovery following prolonged prednisolone therapy in infants. J Clin Endocrinol Metab 2013;98:E1936-E1940.

15 Gordijn MS, Rensen N, Gemke RJ, et al. Hypothalamic-pituitary-adrena (HPA) axis suppression after treatment with glucocorticoid therapy for childhood acute lymphoblastic leukaemia. Cochrane Database Syst Rev 2015;89:CD008727

16 Lipworth BJ. Systemic adverse effects of inhaled corticosteroid therapy: A systematic review and meta-analysis. Arch Intern Med 1999;159:941-55

17 Patel L, Wales JK, Kibirige MS, et al. Symptomatic adrenal insufficiency during inhaled corticosteroid treatment. Arch Dis Child 2001;85:330-4.

18 National Asthma E, Prevention P. National Asthma Education and Prevention Program. Expert Panel Report 3 (EPR-3): Guidelines for the Diagnosis and Management of Asthma-Summary Report 2007. J Allergy Clin Immunol 2007;120(5 Suppl):S94-138.

19 Graber AL, Ney RL, Nicholson WE, et al. Natural History of Pituitary-Adrena recovery Following Long-Term Suppression with Corticosteroids1. J Clin Endocrinol Metab 1965;25:11-16.

20 Meakin JW, Tantongco MS, Crabbé J, et al. Evaluation of pituitaryadrenocortical function in patients with rheumatoid arthritis following steroid therapy. Ann N Y Acad Sci 1960;86:1109-14.

21 Molimard M, Girodet PO, Pollet C, et al. Inhaled corticosteroids and adrenal insufficiency: prevalence and clinical presentation. Drug Saf 2008;31:769-74.

22 Kirkgoz T, Guran T. Primary adrenal insufficiency in children: Diagnosis and management. Best Pract Res Clin Endocrinol Metab 2018;32:397-424.

23 Liu D, Ahmet A, Ward L, et al. A practical guide to the monitoring and management of the complications of systemic corticosteroid therapy. Allergy Asthma Clin Immunol 2013;9:30.

24 Bayman E, Drake AJ. Adrenal suppression with glucocorticoid therapy: still a problem after all these years? Arch Dis Child 2017;102:338.2-9.

25 Dörr HG, Wollmann HA, Hauffa BP, et al. Mortality in children with classic congenital adrenal hyperplasia and 21-hydroxylase deficiency (CAH) in Germany. BMC Endocr Disord 2018;18:37

26 Bornstein SR, Allolio B, Arlt W, et al. Diagnosis and treatment of primary adrenal insufficiency: An endocrine society clinical practice guideline. J Clin Endocrinol Metab 2016;101:364-89.

27 Haus E. Chronobiology in the endocrine system. Adv Drug Deliv Rev 2007:59(9-10):985-1014.

28 Murphy H, Livesey J, Espiner EA, et al. The low dose ACTH test-a further word of caution. J Clin Endocrinol Metab 1998:83:712-3.
29 Wade M, Baid S, Calis K, et al. Technical details influence the diagnostic accuracy of the 1 microg ACTH stimulation test. Eur J Endocrinol 2010;162:109-13.

30 Cartaya J, Misra M. The low-dose ACTH stimulation test: is 30 minutes long enough? Endocr Pract 2015;21:508-13.

31 Hindmarsh PC. Management of the child with congenital adrenal hyperplasia. Best Pract Res Clin Endocrinol Metab 2009;23:193-208.

32 Mitchell AL, Napier C, Asam M, et al. Saving lives of in-patients with adrenal insufficiency: implementation of an alert scheme within the Newcastle-upon-Tyne Hospitals e-Prescribing platform. Clin Endocrinol 2014;81:937-8

33 Schweiger B, Zeitler P, Eppley S, et al. Using the electronic medical record to improve education in patients at risk for adrenal insufficiency. Int J Pediatr Endocrinol 2010;2010:964525.

34 Linder BL, Esteban NV, Yergey AL, et al. Cortisol production rate in childhood and adolescence. J Pediatr 1990;117:892-6.

35 Kerrigan JR, Veldhuis JD, Leyo SA, et al. Estimation of daily cortisol production and clearance rates in normal pubertal males by deconvolution analysis. J Clin Endocrinol Metab 1993:76:1505-10.

36 Speiser PW, Arlt W, Auchus RJ, et al. Congenital Adrenal Hyperplasia Due to Steroid 21-Hydroxylase Deficiency: An Endocrine Society Clinical Practice Guideline. J Clin Endocrinol Metab 2018;103:4043-88.

37 Patti G, Guzzeti C, Di lorgi N, et al. Central adrenal insufficiency in children and adolescents. Best Pract Res Clin Endocrinol Metab 2018;32:425-44.

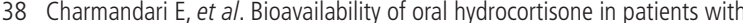
congenital adrenal hyperplasia due to 21-hydroxylase deficiency. J Endocrinol 2001;169:65-70.

39 Melby JC. Clinical pharmacology of systemic corticosteroids. Annu Rev Pharmacol Toxicol 1977;17:511-27.

40 Peters CJ, Hill N, Dattani MT, et al. Deconvolution analysis of 24-h serum cortisol profiles informs the amount and distribution of hydrocortisone replacement therapy. Clin Endocrinol 2013;78:347-51.

41 Bonfig W, Bechtold S, Schmidt H, et al. Reduced final height outcome in congenital adrenal hyperplasia under prednisone treatment: deceleration of growth velocity during puberty. J Clin Endocrinol Metab 2007;92:1635-9.

42 Punthakee Z, Legault L, Polychronakos C. Prednisolone in the treatment of adrenal insufficiency: a re-evaluation of relative potency. J Pediatr 2003;143:402-5.

43 Rivkees SA. Dexamethasone therapy of congenital adrenal hyperplasia and the myth of the "Growth Toxic" glucocorticoid. Int J Pediatr Endocrinol 2010;2010:1-7.

44 Mallappa A, Sinaii N, Kumar P, et al. A phase 2 study of Chronocort, a modifiedrelease formulation of hydrocortisone, in the treatment of adults with classic congenital adrenal hyperplasia. J Clin Endocrinol Metab 2015;100:1137-45.

45 Diurnal's Chronocort fails in phase 3 congenital adrenal hyperplasia trial. 2018 https://www.pharmaceutical-business-review.com/news/diurnals-chronocortphase-3-trial/ (updated 30 Oct 2018).

46 Merke DP, Cho D, Calis KA, et al. Hydrocortisone suspension and hydrocortisone tablets are not bioequivalent in the treatment of children with congenital adrenal hyperplasia. J Clin Endocrinol Metab 2001;86:441-5.

47 C Andersson Åsa, Lindemalm S, Eksborg S. Dividing the tablets for children good or bad?. Pharm Methods 2016;7:23-7.

48 Madathilethu J, Roberts M, Peak M, et al. Content uniformity of quartered hydrocortisone tablets in comparison with mini-tablets for paediatric dosing. BMJ Paediatr Open 2018;2:e000198.

49 Barillas JE, Eichner D, Van Wagoner R, et al. latrogenic cushing syndrome in a child with congenital adrenal hyperplasia: Erroneous compounding of hydrocortisone. The Journal of Clinical Endocrinology \& Metabolism 2018:103:7-11.

50 Neumann U, Burau D, Spielmann S, et al. Quality of compounded hydrocortisone capsules used in the treatment of children. Eur J Endocrinol 2017;177:239-42.

51 Manchanda A, Laracy M, Savji T, et al. Stability of an alcohol-free, dye-free hydrocortisone (2 mg/ml) compounded oral suspension. Int J Pharm Compd 2018;22:66-75.

52 Sarafoglou K, Gonzalez-Bolanos MT, Zimmerman CL, et al. Comparison of cortisol exposures and pharmacodynamic adrenal steroid responses to hydrocortisone suspension vs. commercial tablets. J Clin Pharmacol 2015:55:452-7.

53 Spomer N, Klingmann V, Stoltenberg I, et al. Acceptance of uncoated minitablets in young children: results from a prospective exploratory cross-over study. Arch Dis Child 2012;97:283-6.

54 Klingmann V, Spomer N, Lerch C, et al. Favorable acceptance of mini-tablets compared with syrup: a randomized controlled trial in infants and preschool children.J Pediatr 2013:163:1728-32. 
55 Neumann U, Whitaker MJ, Wiegand S, et al. Absorption and tolerability of taste-masked hydrocortisone granules in neonates, infants and children under 6 years of age with adrenal insufficiency. Clin Endocrinol 2018:88:21-9.

56 Bhogal SK, Zemek RL, Ducharme F. Cochrane Airways Group. Written action plans for asthma in children. Cochrane Database Syst Rev 2006;301:CD005306

57 De Vroede M, Beukering R, Spit M, et al. Rectal hydrocortisone during stress in patients with adrenal insufficiency. Arch Dis Child 1998;78:544-7.

58 Be Prepared for An Emergency!. 2018 https://www.caresfoundation.org/ emergency-medical-care/.

59 Newfoundland and Labrador paramedics can now administer hydrocortisone. 2018 http://www.thelabradorian.ca/news/newfoundland-and-labradorparamedics-can-now-administer-hydrocortisone-242235/.

60 Charmandari E, Lichtarowicz-Krynska EJ, Hindmarsh PC, et al. Congenital adrenal hyperplasia: management during critical illness. Arch Dis Child 2001;85:26-8
61 Webb EA, Krone N. Current and novel approaches to children and young people with congenital adrenal hyperplasia and adrenal insufficiency. Best Pract Res Clin Endocrinol Metab 2015;29:449-68.

62 Cortet C, Barat P, Zenaty D, et al. Group 5: Acute adrenal insufficiency in adults and pediatric patients. Ann Endocrinol 2017;78:535-43.

63 Lubitz DS, Seidel JS, Chameides L, et al. A rapid method for estimating weight and resuscitation drug dosages from length in the pediatric age group. Ann Emerg Med 1988;17:576-81.

64 Paragliola RM, Papi G, Pontecorvi A, et al. Treatment with synthetic glucocorticoids and the hypothalamus-pituitary-adrenal Axis. Int J Mol Sci 2017;18:2201.

65 Ishii T, Adachi M, Takasawa K, et al. Incidence and characteristics of adrenal crisis in children younger than 7 years with 21-hydroxylase deficiency: A nationwide survey in Japan. Horm Res Paediatr 2018;89:166-71.

66 Adrenal insufficiency: Emergency instructions. 2018 http://pedsendo.org/ patients_families/pdf/AITemplateLetter.pdf. 